Case Report

\title{
A Long-Term Survivor with Tetralogy of Fallot Treated Only with the Classical Blalock-Taussig Shunt
}

\author{
Yu Yamada ${ }^{D},{ }^{1}$ Tomoko Ishizu ${ }^{D},{ }^{1}$ Hidekazu Tsuneoka, ${ }^{1}$ Yutaka Eki, ${ }^{2}$ \\ and Hitoshi Horigome $\mathbb{1 i}^{3}$ \\ ${ }^{1}$ Department of Cardiology, Faculty of Medicine, University of Tsukuba, Ibaraki, Japan \\ ${ }^{2}$ Department of Cardiology, Hitachi General Hospital, Ibaraki, Japan \\ ${ }^{3}$ Department of Pediatrics, University of Tsukuba, Ibaraki, Japan \\ Correspondence should be addressed to Tomoko Ishizu; tomoco@md.tsukuba.ac.jp
}

Received 22 April 2018; Revised 21 July 2018; Accepted 1 August 2018; Published 19 August 2018

Academic Editor: Tayfun Sahin

Copyright (c) $2018 \mathrm{Yu}$ Yamada et al. This is an open access article distributed under the Creative Commons Attribution License, which permits unrestricted use, distribution, and reproduction in any medium, provided the original work is properly cited.

\begin{abstract}
The prognosis of tetralogy of Fallot (TOF) treated only with Blalock-Taussig shunt (BTS) operation is unclear. A woman with TOF underwent classic BTS operation at 10 years of age. Despite no medication, she delivered two children and worked without apparent heart failure. At 72 years of age, she complained of dyspnea on exertion and leg edema. The cardiac angiogram revealed a wellpatent BTS and severely stenotic right ventricular outflow tract. Right heart catheterization showed adequately maintained pulmonary blood flow with slight pulmonary arterial hypertension. Her unexpected yet favorable outcome reaffirms the importance of structural and functional self-adaptation even with cyanosis. If she had undergone a valve-sparing corrective surgery in adolescence, much better quality of life and outcome could have been expected.
\end{abstract}

\section{Introduction}

Tetralogy of Fallot (TOF) is the most common cause of cyanotic congenital heart disease, and Blalock-Taussig shunt (BTS) operation is considered the first-step management for maintaining pulmonary blood flow in TOF patients. Complete transventricular repair of TOF is the standard surgical treatment that should be performed in infancy or early childhood [1]. Long-term survival has improved because it is associated with lower operative mortality $[2,3]$. However, the prognosis of patients with TOF treated by only palliative operation remains unclear. We describe a patient with TOF treated by classic BTS operation who lived a productive life without obvious symptoms in the long term.

\section{Case Presentation}

A woman with TOF underwent left classic BTS operation by the late cardiac surgeon Professor Shigeru Sakakibara at the Tokyo Women's Medical College, Tokyo, Japan, in the 1950s when she was 10 years old. She stopped visiting the hospital a few years postoperatively because she did not have difficulty performing daily activities. Subsequently, she got married at 25 years of age and gave birth to two children at 29 years of age without special gynecological care at a local hospital. She kept working on a production line while raising her children without experiencing symptoms of heart failure.

At 70 years of age, she was found to have a low oxygen saturation during a health examination program, but she did not seek hospital care. She developed dyspnea and leg edema when she was 72 years old, and then diuretic was started for a diagnosis of heart failure at a local clinic. When she was referred to our hospital for further evaluation, her symptoms of heart failure were comparable with the New York Heart Association (NYHA) functional class III. Her oxygen saturation was $88 \%$ on room air at rest. Her heart examination revealed a continuous murmur (Levine III/VI) and systolic ejection murmur (IV/VI) in the second right sternal border. Laboratory data showed the following values (reference ranges): hemoglobin level $15.7 \mathrm{~g} / \mathrm{dl}$, hematocrit $44.5 \%$, platelet count $19.7 \times 10^{4} / \mu \mathrm{l}$, prothrombin time 11.4 seconds, 98.5\%, D-dimer level $1.2 \mu \mathrm{g} / \mathrm{dl}(<1.0 \mu \mathrm{g} / \mathrm{dl})$, 


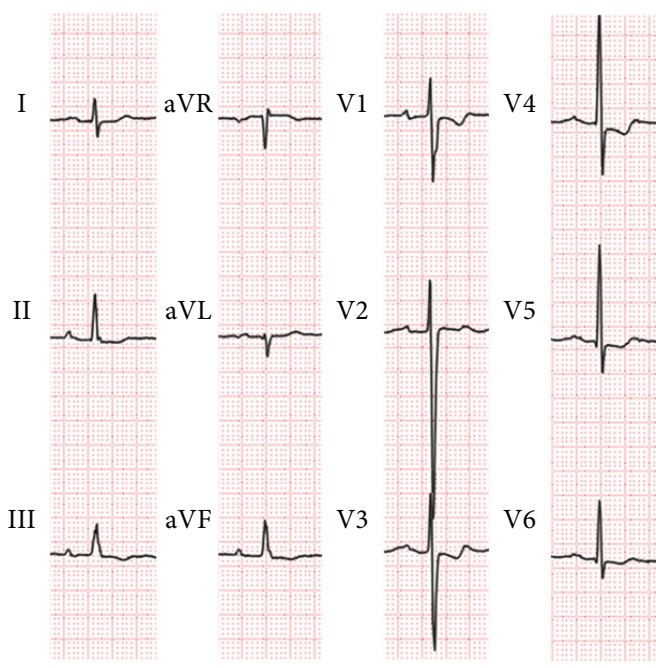

(a)

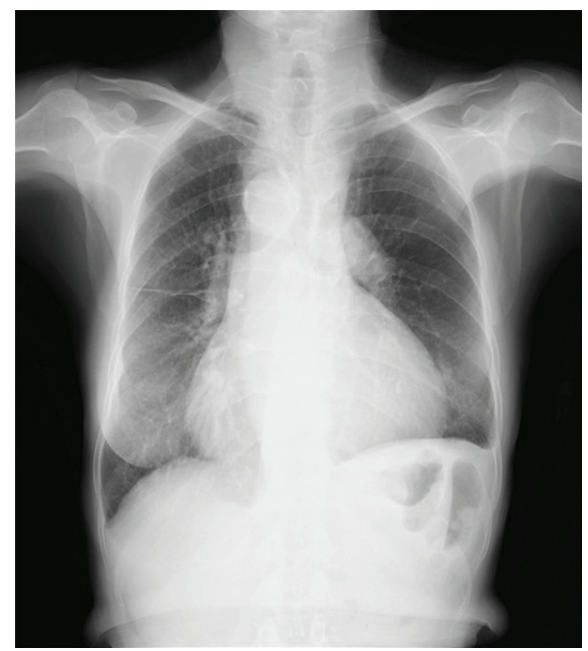

(b)

FIgURE 1: Electrocardiography and the chest X-ray. (a) Electrocardiogram shows normal sinus rhythm at 75 beats/min with a prolonged PR interval; negative T in leads II, III, and aVF; and ST depression in V1 and V4-6. (b) Chest radiograph reveals a cardiothoracic ratio of 66\%, right-sided aortic arch, and dilated pulmonary arteries.

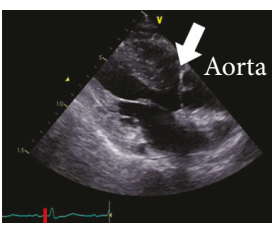

(a)

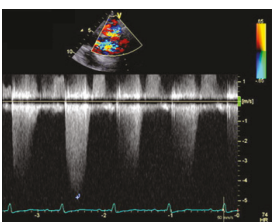

(d)

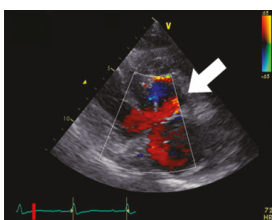

(b)

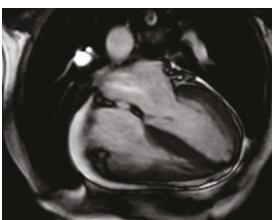

(e)

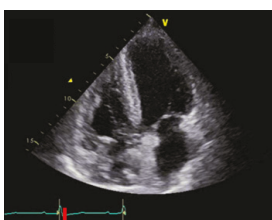

(c)

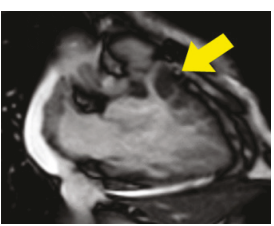

(f)

FIgURE 2: Transthoracic echocardiogram and cardiac magnetic resonance imaging (CMRI). (a) Parasternal long-axis view shows the ventricular septal defect (VSD) (white arrow) and overriding of the aorta. (b) Color Doppler image in the long-axis view shows two shunts through the VSD (white arrow). (c) Apical four-chamber view shows the hypertrophic right ventricle. (d) There is an RV outflow obstruction with a peak velocity of $4.9 \mathrm{~m} / \mathrm{s}$. (e) Analysis of CMRI reveals a normal RV end-diastolic volume (76 ml), reduced RV ejection fraction of $28 \%$, and preserved left ventricular ejection fraction of $60 \%$. (f) CMRI scan shows subvalvular pulmonary stenosis (yellow arrow).

creatinine level $1.35 \mathrm{mg} / \mathrm{dl}(0.4-0.8 \mathrm{mg} / \mathrm{dl})$, and serum braintype natriuretic peptide level $210 \mathrm{pg} / \mathrm{ml}(<18.4 \mathrm{pg} / \mathrm{ml})$. A chest radiograph revealed a cardiothoracic ratio of $66 \%$, right-sided aortic arch, and prominently dilated PA without pulmonary congestion (Figure 1(a)). The electrocardiogram showed sinus rhythm with a prolonged PR interval and ST-T segment abnormalities (Figure 1(b)). The echocardiogram showed a large ventricular septal defect with a bidirectional, mainly left-to-right shunt, overriding the aorta, right ventricular (RV) hypertrophy, and a stenotic RV outflow tract with a peak velocity of $4.9 \mathrm{~m} / \mathrm{s}$ (Figure 2). Left ventricular (LV) diastolic indices of echocardiogram were as follows: peak E velocity $80 \mathrm{~cm} / \mathrm{s}$, E/A 0.72, septal $\mathrm{E}^{\prime}$ velocity $4.1 \mathrm{~cm} / \mathrm{s}$, lateral $\mathrm{E}^{\prime}$ velocity $3.5 \mathrm{~cm} / \mathrm{s}$, and average $\mathrm{E} / \mathrm{E}^{\prime}$ 21. Abnormal relaxation pattern of transmitral flow, low $\mathrm{E}^{\prime}$ velocity, and high $\mathrm{E} / \mathrm{E}^{\prime}$ suggested the existence of LV diastolic dysfunction. The cardiac magnetic resonance imaging scan showed reduced RV ejection fraction (EF) of $28 \%$ and preserved LVEF of $60 \%$ with a LV end-diastolic volume index of $103 \mathrm{ml} / \mathrm{m}^{2}$ (Figures 2(e) and 2(f)). There was no abnormality in the pulmonary valve (PV), and the diameter of the PV annulus was $24 \mathrm{~mm}$. The catheter angiogram revealed a patent BTS and severe stenosis at the ostium of the left PA (Figure 3). Right heart catheterization showed a normal PA wedge pressure (systolic/diastolic/ mean pressure: $15 / 9 / 8 \mathrm{mmHg}$ ), mildly elevated PA pressure (systolic/diastolic/mean pressure: 35/20/30 $\mathrm{mmHg}$ ), elevated RV systolic and end-diastolic pressure (135/ $20 \mathrm{mmHg})$, mean right atrial pressure $(11 \mathrm{mmHg})$, and systolic and end-diastolic LV pressure (149/23 $\mathrm{mmHg}$ ). The pressure gradient between the PA and right ventricle was $117 \mathrm{mmHg}$. Cardiac output calculated by the Fick principle 


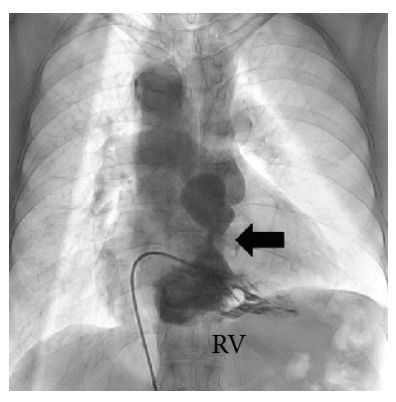

(a)

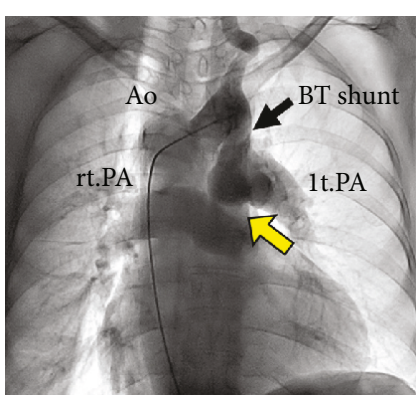

(b)

FIGURE 3: Catheter angiography. (a) Right ventriculogram shows subvalvular pulmonary stenosis (black arrow). (b) Aortogram shows a rightsided aortic arch and patent Blalock-Taussig shunt. There is stenosis at the ostium of the left pulmonary artery (yellow arrow) and both pulmonary artery aneurysms. Ao: Aorta; BT shunt; Blalock-Taussig shunt; lt.PA: left pulmonary artery; rt.PA: right pulmonary artery; RV: right ventricle.

Table 1: Previous reports in PubMed of unoperated TOF surviving over 70 years old.

\begin{tabular}{lccccc}
\hline Number & Author (year) & Age & Gender & Symptom or reason of admission & Other cardiac complications \\
\hline 1 & Thomas et al. (1987) [5] & 77 & Male & Dyspnea & Ductus arteriosus, mitral regurgitation \\
2 & Fernicola et al. (1993) [6] & 74 & Male & Dyspnea & Mitral prolapse \\
3 & Ishida et al. (2001) [7] & 71 & Male & Dyspnea & None \\
4 & Bielik et al. (2005) [8] & 74 & Male & Syncope & None \\
5 & Tanaka et al. (2005) [9] & 72 & Female & Dyspnea & None \\
6 & Yang et al. (2005) [10] & 73 & Male & Dyspnea & None \\
7 & Alonso et al. (2007) [11] & 86 & Male & Chest pain & Coronary artery disease \\
8 & Nieves et al. (2007) [12] & 70 & Female & Dyspnea & None \\
9 & Stanescu et al. (2008) [13] & 75 & Male & Dyspnea & Quadricuspid aortic valve \\
10 & Subhawoang et al. (2009) [14] & 87 & Female & Cerebral infraction & None \\
11 & Sousa et al. (2013) [15] & 72 & Female & Dyspnea & Endocarditis \\
\hline
\end{tabular}

was $2.91 / \mathrm{min}$, and pulmonary vascular resistance index was 5.95 Wood units $\cdot \mathrm{m}^{2}$. The brain's magnetic resonance imaging scan showed no significant abnormalities. She started to take diuretics and home oxygen inspiration therapies; her heart failure symptom improved to NYHA II. Based on the clinical and hemodynamic assessments and her age, we decided not to perform radical operation.

\section{Discussion}

The patient was fortunate to have a patent right ventricular outflow tract (RVOT) that allowed her to live for ten years without surgery. The combination of the classic BTS at age 10 and the patent RVOT provided enough pulmonary blood flow to allow her to survive into her seventies. The use of the left classic BTS in the setting of a right aortic arch created a source of pulmonary blood flow that could grow along with her. Also, the RVOT must have grown along with her somatic growth [4].

Previous reports in PubMed of unoperated TOF surviving over 70 years old are shown in Table 1 [5-15]. There are rarely reported studies on long-term outcome about patients with TOF treated by only palliative operation.

Prolonged survival of patients with uncorrected TOF is often associated with a well-developed left ventricle, initially mild pulmonary stenosis, or well-maintained pulmonary blood flow by such as systemic to pulmonary collaterals or persistent patent ductus arteriosus. Furthermore, in our case, there was no history of significant organ dysfunction due to hypoxia, and no major complication of adult patients with uncorrected TOF such as brain abscess or infective endocarditis. Compared to previous reports (Table 1), it is an important thing that she gave birth to two children without significant symptoms of heart failure. In the case reported by Sousa et al. [15], the patient gave birth to one child without complications; however, her subpulmonary stenosis was very mild (maximum gradient of $31 \mathrm{mmHg}$ ) and her pulmonary blood flow was well maintained (Qp/Qs $=0.9$ ). In our case, appropriately adjusted pulmonary blood flow by BTS might enable her to give birth to two children safely.

This patient had favorable anatomy that allowed her to live for a long time, but there was evidence of biventricular dysfunction accompanied with elevated right and left ventricular end-diastolic pressure. It might be caused by longterm pressure overload and cyanotic state. Although the diameter of the PV annulus was measured in her seventies, the size of $24 \mathrm{~mm}$ must have been acceptable for valvesparing corrective surgery [16-18]. If she had undergone a valve-sparing corrective surgery in adolescence, much better quality of life and outcome could have been expected. 


\section{Conclusion}

This case shows that classical BTS has a potential of longterm patency with good functional capacity. Appropriately adjusted pulmonary blood flow by BTS may cause longterm survival and a productive life in patients with TOF.

\section{Conflicts of Interest}

The authors declare that there are no conflicts of interest regarding the publication of this paper.

\section{References}

[1] G. S. Van Arsdell, G. S. Maharaj, J. Tom et al., "What is the optimal age for repair of tetralogy of Fallot?," Circulation, vol. 102, Supplement 3, pp. III-123-III-129, 2000.

[2] G. Nollert, T. Fischlein, S. Bouterwek, C. Böhmer, W. Klinner, and B. Reichart, "Long-term survival in patients with repair of tetralogy of Fallot: 36-year follow-up of 490 survivors of the first year after surgical repair," Journal of the American College of Cardiology, vol. 30, no. 5, pp. 1374-1383, 1997.

[3] E. J. Hickey, G. Veldtman, T. J. Bradley et al., "Late risk of outcomes for adults with repaired tetralogy of Fallot from an inception cohort spanning four decades," European Journal of Cardio-Thoracic Surgery, vol. 35, no. 1, pp. 156-164, 2009.

[4] E. T. Ross, J. M. Costello, C. L. Backer, L. M. Brown, and J. D. Robinson, "Right ventricular outflow tract growth in infants with palliated tetralogy of Fallot," The Annals of Thoracic Surgery, vol. 99, no. 4, pp. 1367-1372, 2015.

[5] S. H. Thomas, P. Bass, H. Pambakian, and J. H. Marigold, "Cyanotic tetralogy of Fallot in a 77 year old man," Postgraduate Medical Journal, vol. 63, no. 739, pp. 361-362, 1987.

[6] D. J. Fernicola, V. R. Boodhoo, and W. C. Roberts, "Prolonged survival (74 years) in unoperated tetralogy of Fallot with associated mitral valve prolapse," The American Journal of Cardiology, vol. 71, no. 5, pp. 479-483, 1993.

[7] Y. Ishida, M. Kawasuji, N. Sakakibara et al., "A case report of total repair in a 71-year-old patient with tetralogy of Fallot," Kyobu Geka, vol. 54, no. 3, pp. 225-227, 2001.

[8] H. Bielik, M. A. Ohlow, B. Hügl, K. Reinig, R. Gröger, and B. Lauer, "First diagnosis of Fallot tetralogy in a 74-year-old man," Zeitschrift für Kardiologie, vol. 94, no. 3, pp. 205-210, 2005.

[9] S. Tanaka, N. Kikuchi, N. Hirakawa et al., "Prolonged survival in a female with untreated tetralogy of Fallot," Journal of UOEH, vol. 27, no. 2, pp. 189-195, 2005.

[10] X. Yang, L. J. Freeman, and C. Ross, "Unoperated tetralogy of Fallot: case report of a natural survivor who died in his 73rd year; is it ever too late to operate?," Postgraduate Medical Journal, vol. 81, no. 952, pp. 133-134, 2005.

[11] A. Alonso, B. C. Downey, and J. T. Kuvin, "Uncorrected tetralogy of Fallot in an 86-year-old patient," The American Journal of Geriatric Cardiology, vol. 16, no. 1, pp. 38-41, 2007.

[12] O. N. Nieves and J. E. López, "Uncorrected tetralogy of Fallot with agenesis of the left pulmonary artery in a 70-year-old elderly female," Boletin de la Asociacion Medica de Puerto Rico, vol. 99, no. 3, pp. 226-229, 2007.

[13] C. Stanescu and K. Branidou, "A case of 75-year-old survivor of unrepaired tetralogy of Fallot and quadricuspid aortic valve," European Journal of Echocardiography, vol. 9, no. 1, pp. 167-170, 2008.

[14] T. K. Subhawong and O. Teytelboym, "Survival to the age of 87 years in a woman with unoperated tetralogy of Fallot," Journal of Radiology Case Reports, vol. 3, no. 8, pp. 14-17, 2009.

[15] P. Sousa, W. Santos, N. Marques et al., "A 72-year-old woman with an uncorrected tetralogy of Fallot presenting with possible pulmonary endocarditis: a case report," Journal of Medical Case Reports, vol. 7, no. 1, p. 150, 2013.

[16] R. D. Stewart, C. L. Backer, L. Young, and C. Mavroudis, "Tetralogy of Fallot: results of a pulmonary valve-sparing strategy," The Annals of Thoracic Surgery, vol. 80, no. 4, pp. 1431-1439, 2005.

[17] M. Nathan, A. C. Marshall, J. Kerstein et al., "Technical performance score as predictor for post-discharge reintervention in valve-sparing tetralogy of Fallot repair," Seminars in Thoracic and Cardiovascular Surgery, vol. 26, no. 4, pp. 297-303, 2014.

[18] T. Hoashi, K. Kagisaki, Y. Meng et al., "Long-term outcomes after definitive repair for tetralogy of Fallot with preservation of the pulmonary valve annulus," The Journal of Thoracic and Cardiovascular Surgery, vol. 148, no. 3, pp. 802-809, 2014. 


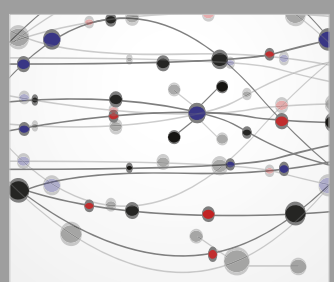

The Scientific World Journal
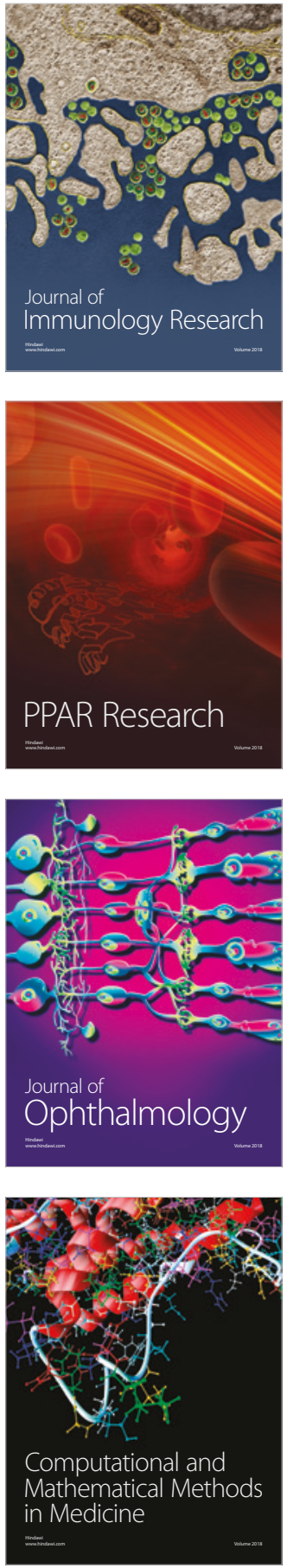

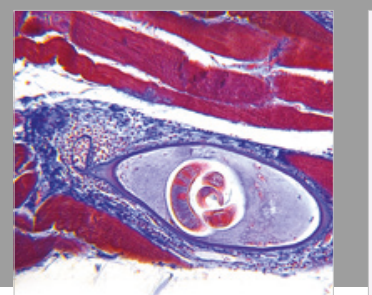

Gastroenterology Research and Practice

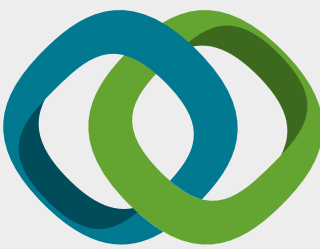

\section{Hindawi}

Submit your manuscripts at

www.hindawi.com
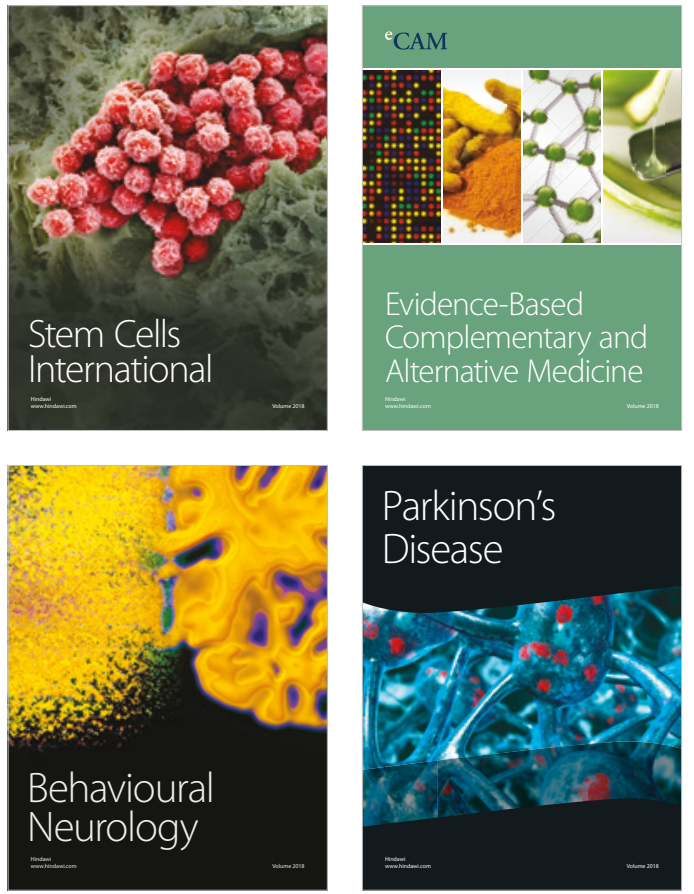

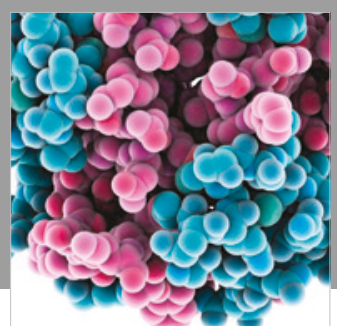

ournal of

Diabetes Research

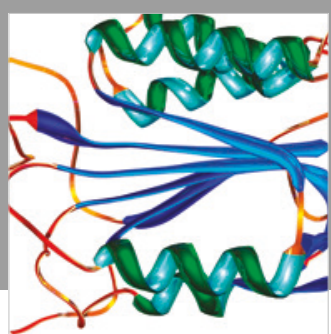

Disease Markers
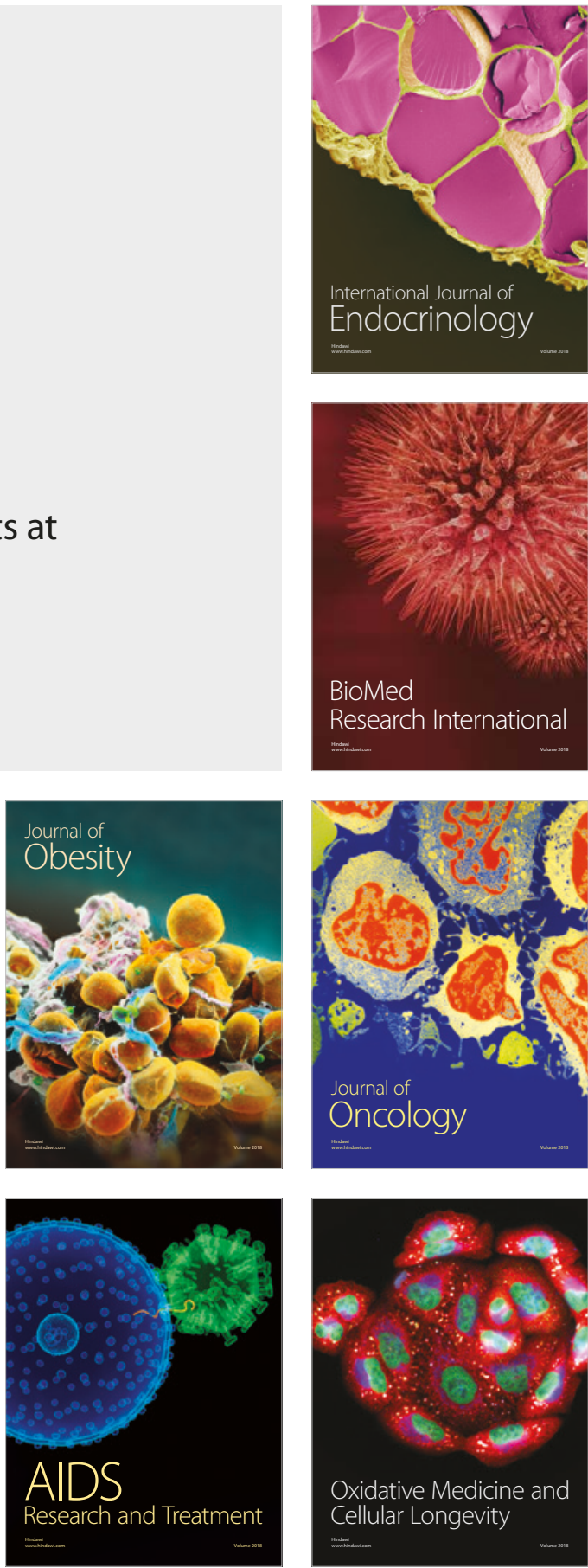